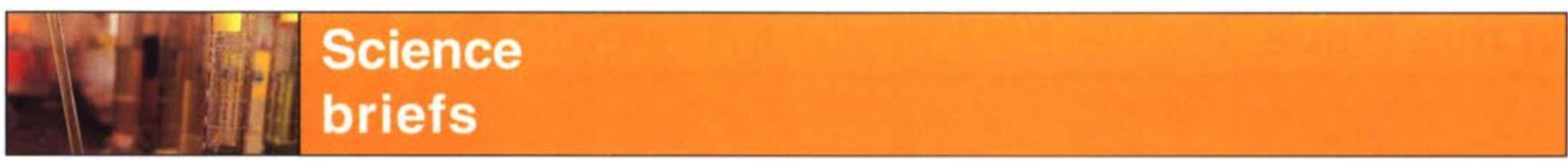

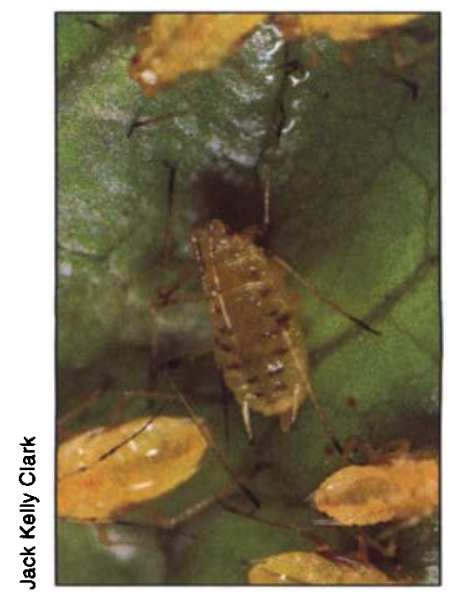

The lettuce aphid, Nasonovia ribis-nigri, has several color forms, ranging from green to orange to pink. The wingless aphids, above, have black markings on the joints of the legs and antennae and on the top of the abdomen. The winged adults, below, are more brown, but also have various black markings.

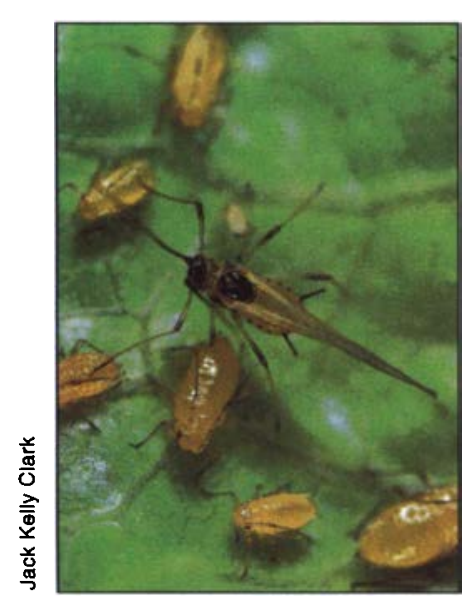

\section{New aphids infest lettuce}

Lettuce growers in the Salinas Valley have met tiny new nemeses - the foxglove aphid and the lettuce aphid. The small bugs crawl between the leaves, deep into the lettuce heads where they are difficult to wash away. Since the aphids are considered a food contaminant, several fields of lettuce were unharvestable this fall, according to Monterey County farm advisor Bill Chaney. He estimates the aphids ruined the equivalent of 100,000 or more cartons of lettuce worth between $\$ 500,000$ and $\$ 750,000$.

The first samples of a new aphid were brought to entomologist Chaney's attention in July. A pest control advisor brought in samples of the small pinkish aphids from a head lettuce field that was being harvested. Chaney identified the pest as the foxglove aphid, Aulacorthum solani. A few weeks later, samples of a second infestation were sent to the California Department of Food and Agriculture lab in Sacramento, which concurred that the aphids were probably the foxglove aphid.

Later in the season, as more and more fields developed infestations, additional samples sent to the lab in Sacramento were identified as the lettuce aphid, Nasonovia ribis-nigri. This pest has been a serious threat to European lettuce production for a number of years, but had never before been seen in California. Chaney thinks the lettuce aphid is to blame for most of the damage.

The foxglove and lettuce aphids look quite similar and have several color forms, ranging from green to orange to pink. Nasonovia has black markings on the joints of the legs and antennae. Some of the wingless aphids have considerable black markings on the top of the abdomen as well. The winged adults are more brown in color, but also have various black markings. Aulacorthum is more commonly green with fewer black markings. However, it is still nearly impossible to distinguish these two species in the field.

Both of these aphids have very short life cycles and populations can build quite rapidly. In cold climates, the lettuce aphid migrates to the roots of the black currant and some other members of the Ribes genus, which are its primary hosts, for the winter. Chaney suspects that the lettuce aphids may continue to survive on secondary hosts, such as lettuce, radicchio, Nic- otiana spp., and some other composites. On the other hand Aulacorthum has a very wide host range and no alternate overwintering host.

Next season, growers may use soil-applied insecticides at planting, but insecticides are expensive and they don't like to apply pesticides before they know the pest is present.

"We are working to try to find better chemical and biological controls for these pests," Chaney says.

Chaney has been monitoring for the lettuce aphid this winter. "We're finding them on weeds right now so I think they are surviving," he says. "I anticipate a problem next year. By March or April we'll have an idea how serious it will be."

\section{Vine mealybug threatens grapes}

A new pest poses a serious new threat to California's grape industry and efforts to reduce pesticide use. The vine mealybug was found this past summer in the San Joaquin Valley.

"If the vine mealybug spreads in California, it will be a very serious problem," says Walter Bentley, UC integrated pest management entomologist. "And everybody expects it to spread."

As the vine mealybug feeds on vines and grape stems it produces tremendous amounts of sticky honeydew, promoting sooty mold and rendering the grapes inedible. It also transmits grape viruses. To date, scientists in the United States and other parts of the world have not been successful controlling the pest with its natural enemies.

The vine mealybug was first found in the United States 4 years ago in the Coachella Valley. It was identified in a tablegrape vineyard south of Arvin in June 1998. Since then small populations have been detected at two other nearby vineyards. A native of the Black Sea area and an established pest of grapes, date palms and figs in South Africa, Egypt, India and Israel, the vine mealybug is a separate, and much more damaging, species than the grape mealybug already found in the San Joaquin Valley.

Since the pest prefers warmer, non-freezing areas, Bentley said the renowned wine producing vineyards of Napa, Mendocino and Sonoma counties, plus those in the mild Central Coast counties of San Luis Obispo and Monterey are threatened by the possible spread of vine mealybug. 